\section{Demise of the fittest: are we destroying our biggest talents?}

\author{
Roald Bahr ${ }^{1,2}$
}

Let us call her Liza. Liza is a very talented volleyball player. Last year, 15 years old, she entered high school at a 'Toppidrettsgymnas', one of 19 schools in Norway which combine an elite training programme with a 3-year senior high school programme. She soon became the starting setter for the school team, the local club's under 17 team, their under 19 team, their second division women's team, as well as for the under 17 and under 19 junior national teams. Her training volume was doubled when school started in August. A few weeks later, her elbows started to hurt. She did adjust her training, but played as many as 35 volleyball matches before she was diagnosed with bilateral 'tennis elbow' in December and finally had to throw in the towel.

\section{THE PATHOPHYSIOLOGY-LIZA DID NOT SUFFER AN 'ACCIDENT'}

Unfortunately, Liza's story is not unique. I could have shared the story of Jonas, Anna, Yuichiro, Hendrik, Karim and many more. Many gifted young athletes' careers have been halted or even ruined by overuse injuries or other health problems caused by what seems like an inappropriate training and competition programme. Using patellofemoral pain as his case, Dye ${ }^{1}$ described the relationship between loading conditions and tissue injury (figure 1). The model depicts how load/loading conditions may exceed the safe load acceptance capacity of the tissue, and describes a zone of load acceptance, the 'zone of homeostasis'. By increasing impact load and volume beyond this, in the 'zone of supraphysiological overload', there is gradual adaptation of tissue properties to the increased load. However, if even greater load and/or volume are applied, structural damage will occur.

Dye's model for patellofemoral pain assumes that the main causative factors are impact load and load volume. This is

\footnotetext{
${ }^{1}$ Department of Sports Medicine, Oslo Sports Trauma Research Center, Norwegian School of Sport Sciences, Oslo, Norway; ${ }^{2}$ Aspetar Orthopaedic and Sports Medicine Hospital, Doha, Qatar

Correspondence to Professor Roald Bahr, Department of Sports Medicine, Oslo Sports Trauma Research Center, Norwegian School of Sport Sciences, PB 4014 Ullevål Stadion, Oslo 0806, Norway; roald.bahr@nih.no
}

likely the case for patellar tendinopathy, as well. Based on their research on risk factors for patellar tendinopathy among elite volleyball players, Lian et al hypothesised that the risk is particularly high for young, promising players transitioning from the junior to the elite senior level. ${ }^{2-4}$ These talents may, from 1 week to the next, move from a relatively 'safe' training environment-for example, practice 2-3 days a week, no weight lifting - to an elite club or sports school that practices daily, including intensive weight and jump training.

\section{TALENT-A DAMOCLEAN SWORD?}

Talented players are also likely to possess superior jumping ability. ${ }^{2} 35$ However, when coupled with sudden increases in strength, muscle mass and training load, it may prove to further amplify their risk of developing tendinopathy by increasing impact load when jumping and landing.

A recent 5-year prospective study lends support to this hypothesis. ${ }^{6} 7$ Visnes et al followed a cohort of 16- to 19-year-old players entering the Toppvolley Norway (TVN) programme, which combines elite volleyball training with a 3-year senior high school boarding school programme. They confirmed that impact load is a key factor. $^{7}$ In a multivariate logistic regression analysis corrected for gender and previous volleyball training, Visnes et al showed that the OR for developing jumper's knee was 2.09 (95\% CI 1.03 to 4.25 ) per centimetre difference in a standard countermovement jump test at the time of inclusion. The higher you jump, the higher the risk! Jumping ability is a key performance factor in volleyball, and test results can differ by as much as $20 \mathrm{~cm}$ within the cohort. In other words, it seems that superior talent may be a Damoclean sword. Similar results have been seen in other sports; baseball pitchers with a talent for high-velocity throwing have an increased risk of overuse injuries to the shoulder and elbow. ${ }^{8-11}$ Interestingly, injury risk also seemed to be higher for those who specialised early, that is, were single-sport athletes the final year before entering TVN. ${ }^{7}$

Load volume is also an important risk factor. The TVN study measured load volume, via match exposure. This was the strongest sports-related predictor for developing jumper's knee, with an OR of 3.88 (95\% CI 1.80 to 8.40 ) for every extra set played per week. ${ }^{6}$ Volleyball training had an OR of 1.72 (95\% CI 1.18 to 2.53) for every additional hour of training each week. ${ }^{6}$ The same observations have been made with other injury types in other sports. Injured baseball pitchers also pitched more months per year, games per year and pitches per game. ${ }^{8}$ Australian cricket players had significantly increased risk of injury if they completed more than 75 throws per week. ${ }^{12}$ Thus, as suggested by Dye ${ }^{1}$ and Lian et al, ${ }^{3}$ load volume is important!

In epidemiological studies in sport, exposure is usually measured as the number of hours of training or match play. This assumes that $1 \mathrm{~h}$ of training by player A equals $1 \mathrm{~h}$ of training by player $\mathrm{B}$. In the current issue we show that measuring training frequency as the number of hours of training or match frequency as the number of sets played may be insufficient. Our observational study on a subset of the TVN cohort shows that jump frequency, the number of jumps per hour of training or per match played, differs substantially between players on the same team. ${ }^{13}$

An important question is why is there such a large difference in training and competition exposure (including the difference observed in jump frequency) between athletes enrolled in the same school programme? A closer look at the data revealed that many of the athletes affected were selected for training camps with junior national teams or their home clubs on weekends and school holidays. ${ }^{6}$ A likely explanation is that these were the most gifted players, and the player and their school, club and national team coach had a shared interest in their playing as much as possible, without much consideration of the risk for injury. Also, whether in a training or a match situation, the more talented players are likely to get more hits, blocks and sets by virtue of their key roles in the team. ${ }^{13}$ So perhaps it should not have come as a surprise that the inter-individual differences in jump frequency are large, even among players on the same squad.

\section{PRACTICAL SOLUTIONS-MONITORING LOAD TO MITIGATE RISK?}

So, then, how do we avoid overloading our biggest talents? Pitch counts have been introduced in baseball, limiting the number of pitches per game and number of months played per year from age 14 to 20 years. ${ }^{8}$ In volleyball and other jumping sports, the best advice we currently can 


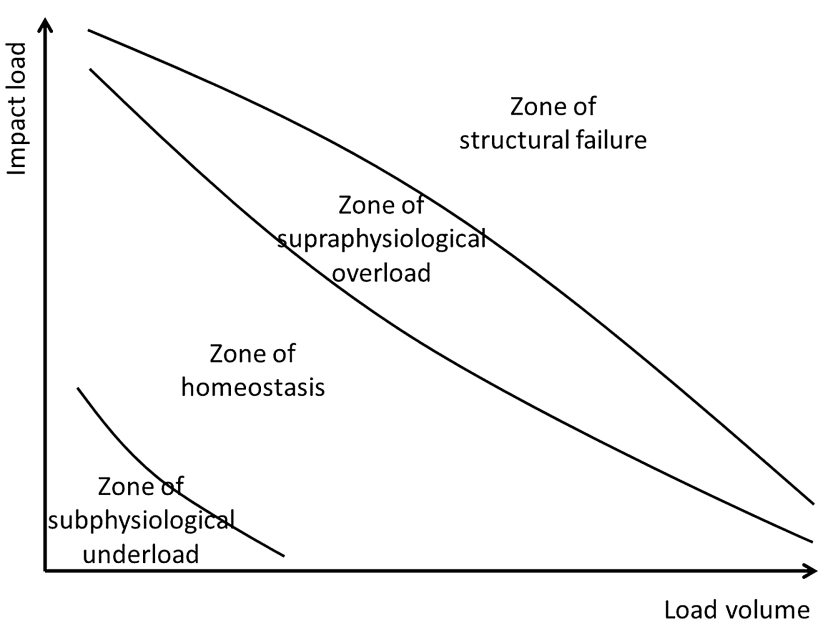

Figure 1 Relationship between structural adaptation and load as modified from Dye's model for patellofemoral pain (2005). ${ }^{1}$ Load volume can be characterised as training volume (frequency, duration, intensity), match frequency, etc. Impact load can be characterised as throwing speed, jump height or other measures of joint load.

give is to keep a close eye on the most talented players, where their jumping ability is a key factor, to ensure that they are not overexposed to training and competition. ${ }^{7}$

The problem is: where is the limit? What is the optimal load which balances maximum training effect with minimum (or acceptable) injury risk? One option could be to monitor athletes for structural changes associated with typical overuse injuries, for example, tendinopathy. In the TVN cohort, semiannual ultrasound examinations revealed that the risk of developing symptoms of jumper's knee was three times higher in tendons with hypoechoic areas at baseline. ${ }^{14}$ Others have made similar observations. ${ }^{15} \quad 16$ However, the same studies also revealed that structural changes are not necessarily associated with symptoms. ${ }^{14-16}$ New ultrasound modalities are emerging, such as ultrasonographic tissue characterisation which captures contiguous transverse images over the length of the tendon. However, future studies are needed to examine whether these techniques could help monitor the response to load in at-risk athlete populations. ${ }^{17}$

Another option would be to introduce jump counts in sports like volleyball and perhaps throw counts in sports like handball. In a series of recent studies based on the novel injury registration methodology developed at the Oslo Sports Trauma Research Center, Clarsen et $a l^{18}{ }^{19}$ have revealed that, in some sports, acute injuries only represent 'the tip of the ice berg'. Overuse injuries represent the main problem; in the case of handball players to the throwing shoulder. ${ }^{19}$ In the current issue we demonstrate how the new methodology can be used on elite players to reveal an association with scapular dyskinesis, rotational range of motion and external rotation strength. The findings may help develop intervention programmes targeting these risk factors for shoulder injury. ${ }^{20}$

Obviously, it would require large prospective studies to establish appropriate limits for throw counts or jump counts. A barrier to this approach is that while it may be easy to do manual pitch counts in baseball (there is only one pitcher), one rally in volleyball may involve multiple jumps by nearly all players on court, often two or three at the same time. Therefore, we were looking for ways to automate jump counts, and hypothesised that a standard triaxial accelerometer could be used to monitor jump frequency. Unfortunately, our experimental study on elite volleyball players showed that we could not distinguish adequately between jumping and non-jumping movements. ${ }^{21}$ Still, more sophisticated inertial sensing systems are emerging, such as non-solid state motion sensors and sensors combining an accelerometer with a gyroscope (personal communication, Jarning JM, Mok K-M, Hansen BH, et al. Application of triaxial accelerometers to estimate jump frequency in volleyball: an attempt to monitor the risk of developing patellar tendinopathy. Sports Biomech 2014). Future research will reveal whether these can be used to monitor jump frequency in real time.

In volleyball (and other jumping sports), jumper's knee is the main risk. ${ }^{21}$ However, each sport has its own characteristic loading pattern and, often, a 'signature' overuse injury to go with it (eg, tennis elbow, golfer's elbow, runner's knee). A number of different sensors already exist which can be used to monitor load in different sports, such as global positioning system devices, heart rate monitors, instrumented cycles, helmets and tennis rackets. As the consumer market in wearable technology expands, it seems a reasonable prediction that the tool box will soon include smart sensors which can help researchers understand overuse injuries and aid coaches in preventing overuse injuries.

But even a volleyball player can get tennis elbow. The setting motion in volleyball involves repetitive elbow extension and forearm pronation. It should not come as a surprise that in Liza's case her elbows failed with the dramatic increase in setting volume. Advanced sensors are not needed to predict that doubling loading volume is a recipe for disaster. We now have the evidence to show that extra caution is needed when managing the gifted athlete.

\section{Competing interests None.}

Provenance and peer review Not commissioned; internally peer reviewed.

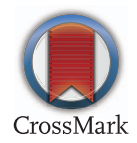

To cite Bahr R. Br J Sports Med 2014;48:1265-1267.

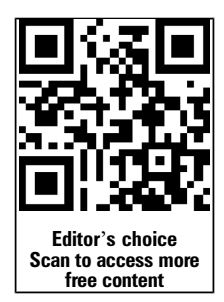

Accepted 5 May 2014

Published Online First 26 May 2014

Br J Sports Med 2014;48:1265-1267. doi:10.1136/bjsports-2014-093832

\section{REFERENCES}

1 Dye $S$. The pathophysiology of patellofemoral pain: a tissue homeostasis perspective. Clin Orthop Relat Res 2005;436:100-10.

2 Lian $\varnothing$, Engebretsen L, Øvrebo RV, et al. Characteristics of the leg extensors in male volleyball players with jumper's knee. Am J Sports Med 1996;24:380-5.

3 Lian $\varnothing$, Refsnes PE, Engebretsen L, et al. Performance characteristics of volleyball players with patellar tendinopathy. Am J Sports Med 2003;31:408-13.

4 Reeser JC, Verhagen E, Briner WW, et al. Strategies for the prevention of volleyball related injuries. $\mathrm{Br} J$ Sports Med 2006;40:594-600.

5 Richards DP, Ajemian SV, Wiley JP, et al. Knee joint dynamics predict patellar tendinitis in elite volleyball players. Am J Sports Med 1996;24:676-83. 
6 Visnes H, Bahr R. Training volume and body composition as risk factors for developing jumper's knee among young elite volleyball players. Scand J Med Sci Sports 2013;23:607-13.

7 Visnes H, Aandahl HÅ, Bahr R. Jumper's knee paradox-jumping ability is a risk factor for developing jumper's knee: a 5-year prospective study. Br J Sports Med 2013;47:503-7.

8 Olsen SJ, Fleisig GS, Dun S, et al. Risk factors for shoulder and elbow injuries in adolescent baseball pitchers. Am J Sports Med 2006;34:905-12.

9 Escamilla R, Fleisig G, Barrentine $S$, et al. Kinematic and kinetic comparisons between American and Korean professional baseball pitchers. Sports Biomech 2002;1:213-28.

10 Petty DH, Andrews JR, Fleisig GS, et al. Ulnar collateral ligament reconstruction in high school baseball players: clinical results and injury risk factors. Am J Sports Med 2004;32:1158-64.

11 Werner SL, Suri M, Guido JA, et al. Relationships between ball velocity and throwing mechanics in collegiate baseball pitchers. J Shoulder Elbow Surg 2008;17:905-8.
12 Saw R, Dennis RJ, Bentley D, et al. Throwing workload and injury risk in elite cricketers. $\mathrm{Br} J$ Sports Med 2011:45:805-8.

13 Bahr MA, Bahr R. Substantial inter-individual and gender differences in jump frequency during training and matches in young elite volleyball players - a risk factor for jumper's knee? Br J Sports Med 2014;48:564.

14 Visnes H, Tegnander A, Bahr R. Ultrasound characteristics of the patellar and quadriceps tendons among young elite athletes. Scand I Med Sci Sports 2014 Feb 24. doi: 10.1111/sms.12191. [Epub ahead of print]

15 Malliaras P, Cook J, Ptasznik R, et al. Prospective study of change in patellar tendon abnormality on imaging and pain over a volleyball season. $\mathrm{Br} J$ Sports Med 2006:40:272-4.

16 Comin J, Cook JL, Malliaras P, et al. The prevalence and clinical significance of sonographic tendon abnormalities in asymptomatic ballet dancers: a 24-month longitudinal study. Br J Sports Med 2013;47:89-92.

17 Scott A, Docking S, Vicenzino B, et al. Sports and exercise-related tendinopathies: a review of selected topical issues by participants of the second International
Scientific Tendinopathy Symposium (ISTS) Vancouver 2012. Br J Sports Med 2013;47:536-44.

18 Clarsen B, Myklebust G, Bahr R. Development and validation of a new method for the registration of overuse injuries in sports injury epidemiology: the Oslo Sports Trauma Research Centre (OSTRC) overuse injury questionnaire. Br J Sports Med 2013:47:495-502.

19 Clarsen B, Bahr R, Heymans MW, et al. The prevalence and impact of overuse injuries in five Norwegian sports: application of a new surveillance method. Scand J Med Sci Sports 2014 Mar 30. doi:10.1111/sms.12223. [Epub ahead of print].

20 Clarsen B, Bahr R, Andersson SH, et al. Glenohumeral rotation, external rotation strength and scapular control are risk factors for shoulder injuries among elite male handball players: a prospective cohort study. $\mathrm{Br} J$ Sports $\mathrm{Med}$ 2014:48:579.

21 Lian ØB, Engebretsen L, Bahr R. Prevalence of jumper's knee among elite athletes from different sports: a cross-sectional study. Am J Sports Med 2005;33:561-7. 